$\xi=-1$

\title{
Development of mode choice models of a trip maker for Hyderabad metropolitan city
}

\author{
B. Prasad ${ }^{1 *}$, Kumar Molugaram ${ }^{2}$ \\ ${ }^{1}$ Assistant Professor, Department of Civil Engineering, CMR College of Engineering \& Technology,Kandlakoya, \\ Hyderabad, Telangana, India - 501401 \\ ${ }^{2}$ Professor of Civil Engineering, Department of Civil Engineering, College of Engineering, Osmania University,Hyderabad, India \\ *Corresponding author E-mail:bolliniprasad@cmrcet.org
}

\begin{abstract}
The rapid development of urbanization, population growth and the rapid development of economy resulted in the rapid increase in the total number of motor vehicles in the modern cities of India. Consequently, the importance of forecasting of the travel demand model has been increased in the recent years. Forecasting of the travel demand model involves various stages of trip generation and distribution, mode choice and traffic assignment. Among these stages, the mode choice analysis is a prominent stage as it considers the travelers mode to reach their destination. Further, study of mode choice criteria has become a vital area of research as individual and household sociodemographics exert a strong influence on travel mode choice decisions. There is a huge literature on travel model choice modeling to predict the range of trade-offs of transportation of commuters considering travel time and travel cost. In such literature intercity mode choice behavior has gained significant attention by several authors. In this study an attempt has made in order to calculate the model share of the different modes between the circle to the circle, and it is found that the modal share of 2 -wheeler is $70 \%$, bus is about $23 \%$ and car is about $7 \%$ of the total trips.
\end{abstract}

Keywords: Mode Choice Modeling; Binary Logit Models; Multinomial Logit Models; Trip Maker; And Travel Demand Modeling.

\section{Introduction}

Mode choice analysis is the third step in the conventional fourstep transportation planning model. Trip distribution's zonal interchange analysis yields a set of origin destination tables, which tells where the trips will be made; mode choice analysis allows the modeler to determine what mode of transport will be used. Mode choice is one of the most critical parts of the travel demand modeling process. It is the step where trips between a given origin and destination are split into trips using transit, trips by car pool or as automobile passengers and trips by automobile drivers. A utility function measures the degree of satisfaction that people derive from their choices, and a disutility function represents the generalized cost that is associated with each choice. The most commonly used process for mode split is to use the 'Logit' model. This involves a comparison of the "disutility" or "utility" of travel between two points for the different modes that are available. Disutility is a term used to represent a combination with the travel time, cost and convenience of a mode between an origin and a destination. It is found by placing multipliers (weights) on these factors and adding them together.

Disutility calculations may contain a "mode bias factor" which is used to represent other characteristics or travel modes, which may influence the choice of mode (such as a difference in privacy and comfort between transit and automobiles). The mode bias factor is used as a constant throughout the analysis and is found by an attempt to fit the model to actual travel behavior data. Generally, the disutility equations do not recognize differences within travel modes. For example, a bus system and a rail system with the same time and cost characteristics will have the same disutility values.
There are no special factors that allow for the difference in attractiveness of alternative technologies.

\section{Model split models}

Selection of the transport mode choice[1] by the trip maker is depended upon the various factors like availability of the transport mode, travel time, travel cost, parking fees and availability and access point, etc. based on the above-mentioned factor. There are so many mathematical models developed to know the behavior of the trip maker. Mode Choice Models generally classified mainly intotwo categories which are shown in fig 1.

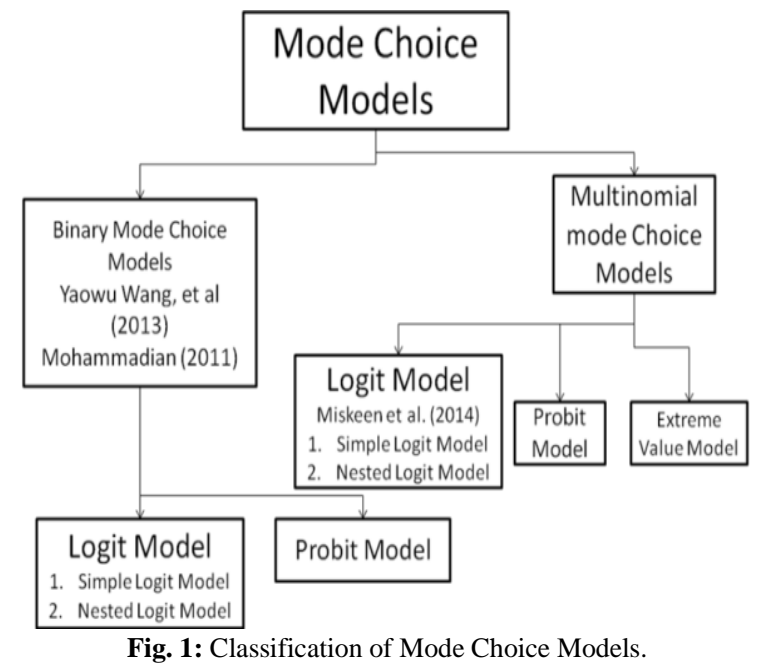

Copyright $\odot$ 2018Mr. B. Prasad, Dr. Kumar Molugaram. This is an open access article distributed under the Creative Commons Attribution

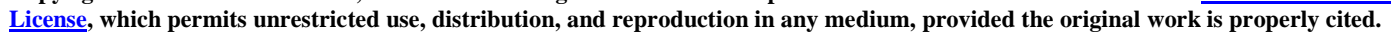


Binary logit model is the simplest form of mode choice and it is categorized into simple and nested logit model. It is used when only two transport mode choices are there for trip maker. The higher utility value mode will be chosen by the trip maker in this case. But in transportation, we have disutility also. The disutility here is the travel cost. The general form of the binary logit model is in equation. 1

The probability of individual i selecting mode $m$ out of two travelling modes available $\mathrm{m}$ and $\mathrm{n}$

$$
\operatorname{Pim}=\frac{\exp (\text { Vim })}{\exp (\operatorname{Vim})+\exp (\text { Vin })}
$$

Where,

Pim is the probability that alternative $\mathrm{m}$ will be selected by individual i

Vim is utility function associated to alternative $\mathrm{m}$ for individual $\mathrm{i}$

Vin is utility function associated to alternative $n$ for individual $i$

Binary logit model have the some limitations that the choice of alternatives in each set should be different. If there are groups of similar or correlated modes application of binary logit model is not valid. In such cases nested logit model can be used relaxes the constraints of the simple logit models allowing correlation between the utilities of the alternatives in common groups. Multinomial logit model [2] is also same as the binary logit model and it is categorized into simple and nested logit model based on the available travelling mode choice set characteristics. Equations of Multinomial logit model are Equations of binary simple and nested logit model only.

If the utilities of some alternatives are correlated in a complex way, the multinomial logit models can make incorrect forecasts regarding the probabilities' mode choice when attributes are associated with one or more traveling alternatives. In this case probit, model is one of the possible methods to overcome this type of problems. This model is developed based on the normal distribution, and it will not work under the strict assumptions as that of logit models. The standard equation for the utility of an alternative $i$ has the form (Horowitz 1991) as shown in equation 2.

$$
\mathrm{Ui}=\mathrm{V}(\mathrm{xi}, \mathrm{s})+\varepsilon \mathrm{ei}
$$

\section{Where,}

Ui is the utility of alternative $\mathrm{i}$

$\mathrm{V}$ is the systematic component of utility function

$\varepsilon$ is the error component of utility function

$\mathrm{xi}$ is the vector of observed attributes of alternative $\mathrm{i}$

$\mathrm{s}$ is the vector of observed characteristics of the individuals of the study area

In simplification of multinomial logit models generalized extreme value models have developed based on the utility maximization

\section{Literature review}

From the past few decades' lot of research has been done in the development of Mode Choice Modeling (MCM) area with different models, different parameters for different cities all over the globe. The present paper discusses the literature carried out in this specific area of research.

To develop the model for the mode choice behavior of a road user different researchers have adopted different methodologies among few are discussed here. Binary probit and logit models are developed to compare the modal behavior and to test the differences of mode choice among the different zones [13]. Evidential neural network (ENN) model is used for predicting an individual travel mode. This model can be also used to support management decision-making and build predictions under uncertainty related to changes in people's behavior, economic context or environment and policy. The presented model uses individuals' characteristics, transport mode specifications and data related to places of work and residence [17]. The fuzzy logic technique was developed in 1965 by LotfiZadeh. The fuzzy logic provides a mechanism for representing linguistic variables such as "many," "low," "medium," "often," "few," etc. On the contrary. The traditional binary set theory describes crisp events, events that either do or do not occur [8]. The theory of fuzzy logic [22] is based on the concept of relative graded membership. It is important to observe that there is an intimate connection between Fuzziness and Complexity [21]. Integrated Hierarchical Information Integration (HII-I) approach allows to include a larger number of attributes in choice experiments by summarizing similar attributes into constructs. In separate sub-experiments, one constructs is described by its attributes while the other constructs are included by summarizing construct values. This approach allows for testing of process equality in order to know if the different sub-experiments may be concatenated into an overall model.Cornelia Richter (2012).

Miskeen et al. (2014) have studied the MCM using a Multinomial logit model which helps in investigating mode choice behavior for non-business trips in the city of Libya and this study also investigates the interest of road users towards the intercity transport[3][4][5][6]. The study was conducted in all main metropolitan areas in Libya. The data required for defining, designing, and validating transferability, contain three categories, such as: (1) socio-economic variables, (2) level of services or supply variables, and (3) trip data.

Kumar et al. (2013) developed a MCM to explore the relationship between travel patterns of commuters and their willingness to adopt an alternate mode. The study also estimated public transport share along with private vehicles. A fuzzy logic model is applied on three work centers, NetajiSubhash Place, Nehru Place and Connaught Place in Delhi (India). The main emphasis of their study was to test the number of public transport policy variables to determine the modal share with respect to personalized and public transport modes. The technique mainly considered the trip characteristics of commuters by using the number of variables affecting the mode choice behavior of commuters with respect to various alternative modes.

JianchuanXianyu (2013)[18] has investigated the decision order of trip chaining and travel mode choice. A house-hold survey is conducted during this study, which can be applied on the coevolutionary approach to capture the interrelationship between travel mode choice and trip chaining. A co-evolutionary logit model is used for modeling the MCM. Three categories of explanatory variables that influence the travel mode and trip chaining of a work tour are considered. Namely individual and household socio-demographics, transportation-relatedmeasures, and activity travel across characteristics. Results of this study provide the approaches for predicting commute mode and trip chaining behavior simultaneously. Cornelia Richter et al. (2012) [7] have done a research that the Hierarchical Information Integration approach is applied on MCM between a regional train, a (hypothetical) regional bus and a car (only available for car users). Lu et al. (2011) [10] have studied a multimodal corridor transportation system with trip-chain costs. The transportation system comprises a subway parallel to a bottleneck-constrained highway between a residential area and a workplace.

Zhihu Zhang, Hongzhi Guan, Huanmei Qin, and YunqiangXue (2013) have conducted a survey on the bus user groups in Jinan city and establish the MNL model as well as SP and RP model. This paper analyzes how the influencing factors such as parking fee, fuel cost, bus ticket price and bus travel time affect the choice proportion of bus travel mode for the bus user groups. A multinomial logit model is used for MCM, and the sensibility of the parking fee is analyzed when the fuel cost is unchanged or increased.

Yaowu Wang, et al (2013) developed the Binary probit and logit models for MCM and compared the modal behavior to verify the differences of mode choice behavior among the three zones in Maryland. They investigated unobserved factors influencing freight mode choices, including truck and rail. Based on the nature as the data source, there are two types of analytical methods in freight modal choice in the literatures: aggregated and disaggre- 
gated models (Winston, 1983). The aggregated model applies an aggregated share of a freight mode at a certain geographical level. This type of model focuses on describing the group behavior of firms, and it is useful to capture general trends and changes due to policies based on general characteristics observed (Shen and Wang, 2012). Disaggregated choice models focus more on individual behavioral aspects of the shipment decision makers. Data are collected from individual shipper, companies.

Arunotayanun and Polak (2011) used a mixed logit model to investigate the prevalence of observed and unobserved taste heterogeneity influencing shippers mode choice behavior based on stated preference data collected in Java, Indonesia. Samimi, Kawamura, and Mohammadian (2011) used binary logit and probit models to explain how truck and rail are chosen by the shippers.

Chandra R. Bhat et al (2010) studied the commute mode choice and the number of non-work stops during the commute using a multinomial logit formulation. Further, the number of commute stops is modeled using an ordered response formulation. Copulabased joint multinomial logit - ordered logit structure, and captures the observed effects of personal, household, residential location, and commute characteristics together with potential unobserved common effects impacting the two choices. The copulabased methodology facilitates model estimation without imposing restrictive distribution assumptions on the dependency structures between the errors in the discrete unordered and ordered choice components [19].

The results of their work indicate the substantial and statistically significant effects of individual and household characteristics on mode choice and stop-making behavior. On the other hand, residential location and commute characteristics seem to affect only to commute mode choice and not commute stop-making behavior. Earlier studies have also pointed out the relatively small or zero effect of commute distances and built environment variables on commute stop-making, especially relative to the effects of demographic variables.

Chandra R. Bhat et al. (2010) used an econometric structure to jointly model the commute mode choice and the number of commute stops in the Boston Metropolitan Area. The commute mode was modeled using a multinomial logit model and developed a copula-based joint framework of tour mode choice and number of stops during the commute.

The purpose of effectively managing demands of urban travel, it is essential to plan a suitable transport system, in addition to dealing with the issues of traffic jam, accidents and environmental pollution, as a result of overflowing number of vehicles.

\section{Analysis and results}

For the porpuse study Hyderabad metropolitan city area has been considered. The study area is mainly consists of 18 circles as given in the Table 1.
Table 1: Number of Circles in the Study Area

\begin{tabular}{llrl}
\hline Circle & Name of the Zone / Circle & Latitude & Longitude \\
No. & & $17.49 \mathrm{~N}$ & $78.57 \mathrm{E}$ \\
\hline 1. & Kapra & $17.38 \mathrm{~N}$ & $78.55 \mathrm{E}$ \\
2. & Uppal & $17.34 \mathrm{~N}$ & $78.55 \mathrm{E}$ \\
3. & L.B. Nagar / Gaddiannaram & $17.37 \mathrm{~N}$ & $78.51 \mathrm{E}$ \\
4. & Erstwhile Circle - I & $17.32 \mathrm{~N}$ & $78.47 \mathrm{E}$ \\
5. & Erstwhile Circle - II & $17.18 \mathrm{~N}$ & $78.24 \mathrm{E}$ \\
6. & Rajendra Nagar & $17.39 \mathrm{~N}$ & $78.43 \mathrm{E}$ \\
7. & Erstwhile Circle - IV & $17.39 \mathrm{~N}$ & $78.43 \mathrm{E}$ \\
8. & Erstwhile Circle - VI & $17.38 \mathrm{~N}$ & $78.47 \mathrm{E}$ \\
9. & Erstwhile Circle - III & $17.41 \mathrm{~N}$ & $78.46 \mathrm{E}$ \\
10. & Erstwhile Circle - V & $17.48 \mathrm{~N}$ & $78.31 \mathrm{E}$ \\
11. & Serilingampally & & \\
& (North) & $17.48 \mathrm{~N}$ & $78.31 \mathrm{E}$ \\
12. & Serilingampally & $17.51 \mathrm{~N}$ & $78.30 \mathrm{E}$ \\
13. & (South) & $17.49 \mathrm{~N}$ & $78.39 \mathrm{E}$ \\
14. & KamachandraPuram and Patancheru & $17.49 \mathrm{~N}$ & $78.46 \mathrm{E}$ \\
15. & Qukatpally & $17.49 \mathrm{~N}$ & $78.50 \mathrm{E}$ \\
16. & Alwal & $17.44 \mathrm{~N}$ & $78.53 \mathrm{E}$ \\
17. & Malkajgiri & $17.43 \mathrm{~N}$ & $78.49 \mathrm{E}$ \\
\hline 18. & Secunderabad Division & & \\
\hline & & & \\
\hline
\end{tabular}

Once disutility are known for the various mode choices between an origin and a destination, the trips are split among various modes based on the relative differences between disutility. The logit equation is used in this step. A large advantage in disutility will mean a high percentage for that mode. Mode splits are calculated to match splits found from actual traveler data. Sometimes a fixed percentage is used for the minimum transit use (percent captive users) to represent travelers who have no automobile available or are unable to use an automobile for their trip.

In this step the matrix for travel time and travel cost is given to calculate the utilities for three modes- Car, Bus and Two wheelers Moreover utility functions for these three modes are also assumed. The utility functions are as follows:

$$
\begin{aligned}
& \mathrm{U}_{\mathrm{CAR}}=-0.06 \mathrm{VTT}_{\mathrm{CAR}}-0.043 \mathrm{TC}_{\mathrm{CAR}}+0.01 \mathrm{WT}_{\mathrm{CAR}} \\
& \mathrm{U}_{\mathrm{TW}}=-0.06 \mathrm{VTT}_{\mathrm{TW}}-0.043 \mathrm{TC}_{\mathrm{TW}}+0.016 \mathrm{WT}_{\mathrm{TW}} \\
& \mathrm{U}_{\mathrm{BUS}}=-0.06 \mathrm{VTT}_{\mathrm{BUS}}-0.043 \mathrm{TC}_{\mathrm{BUS}}+0.012 \mathrm{WT}_{\mathrm{BUS}}
\end{aligned}
$$

Where $\mathrm{VTT}=$ Vehicle travel time, $\mathrm{TC}=$ Travel cost and $\mathrm{WT}=$ Walking time.

Using utility equations the utility matrices for Car, Bus and Two Wheeler were generated and are tabulated as shown in tables 3, 4 and 5 .

The Origin- Destination Matrix (O-D) were developed by conducting the Origin-Destination survey at different locations in each circle to know the number of trips generated and number of trips attracted from circle to circle and the same has tabulated as shown in the table 2. From the table it has been observed that maximum number of trips generated and maximum number of trips attracted by circle 6 only. 
Table 2: Origin- Destination Matrix (O-D)

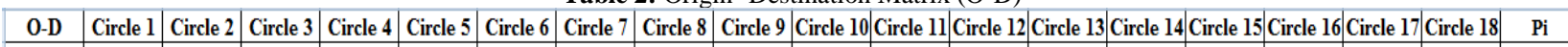

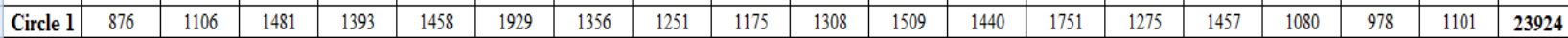

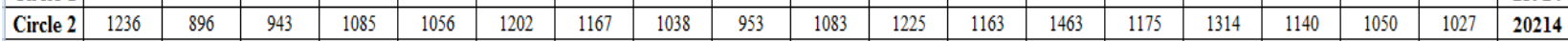

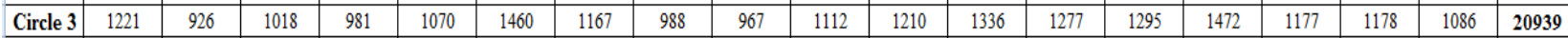

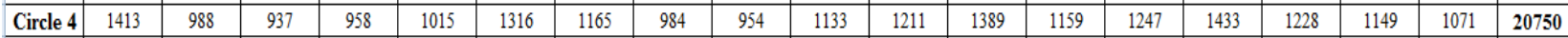
\begin{tabular}{|l|l|l|l|l|l|l|l|l|l|l|l|l|l|l|l|l|l|l|l|}
\hline Circle 5 & 1303 & 1128 & 1066 & 965 & 998 & 1303 & 1236 & 1031 & 1025 & 1165 & 1171 & 1299 & 1680 & 1188 & 1415 & 1190 & 1092 & 1028 & $\mathbf{2 1 2 8 2}$ \\
\hline
\end{tabular}

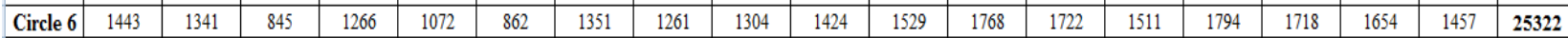

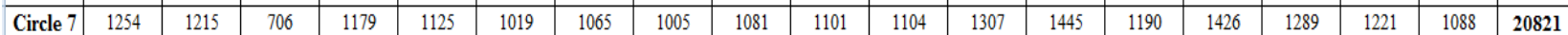

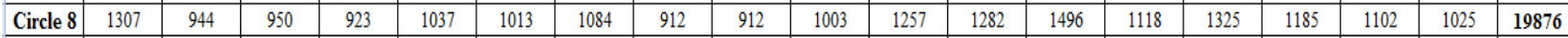

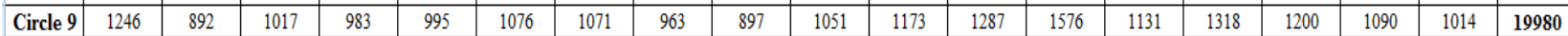

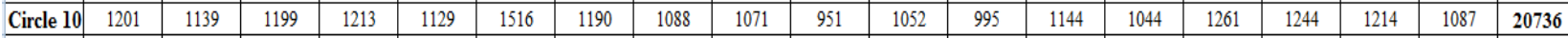

\begin{tabular}{|l|l|l|l|l|l|l|l|l|l|l|l|l|l|l|l|l|l|l|l|}
\hline Circle ll & 1168 & 1183 & 1291 & 1290 & 1173 & 1538 & 1193 & 1095 & 1094 & 1069 & 1062 & 901 & 988 & 1066 & 1207 & 1209 & 1236 & 1099 & $\mathbf{2 0 8 6 1}$ \\
\hline Cris
\end{tabular}

\begin{tabular}{|l|l|l|l|l|l|l|l|l|l|l|l|l|l|l|l|l|l|l|l|}
\hline Circle 12 & 1417 & 1300 & 1365 & 1354 & 1385 & 1577 & 1427 & 1288 & 1213 & 1185 & 994 & 929 & 973 & 1121 & 1285 & 1400 & 1351 & 1207 & $\mathbf{2 2 7 7 2}$ \\
\hline Circe & 1527 & & & & &
\end{tabular}

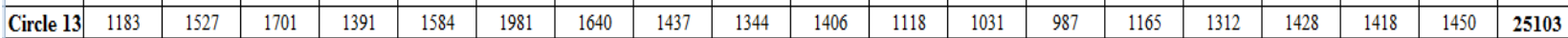

\begin{tabular}{|l|l|l|l|l|l|l|l|l|l|l|l|l|l|l|l|l|l|l|l|}
\hline Circle 14 & 1290 & 1208 & 1292 & 1260 & 1241 & 1353 & 1233 & 1134 & 1152 & 1093 & 1109 & 1086 & 1128 & 1025 & 1107 & 1232 & 1236 & 1120 & $\mathbf{2 1 2 9 9}$ \\
\hline
\end{tabular}

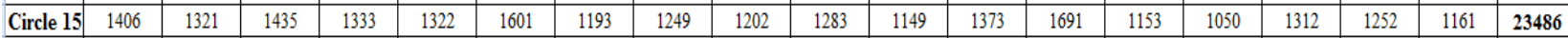
\begin{tabular}{|l|l|l|l|l|l|l|l|l|l|l|l|l|l|l|l|l|l|l|l|}
\hline Circle 16 & 1213 & 1195 & 1259 & 1289 & 1268 & 1434 & 1263 & 1240 & 1105 & 1230 & 1639 & 1426 & 1700 & 1238 & 1288 & 976 & 1140 & 1101 & $\mathbf{2 3 0 0 5}$ \\
\hline
\end{tabular}

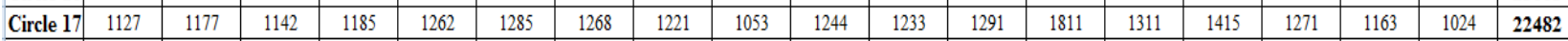

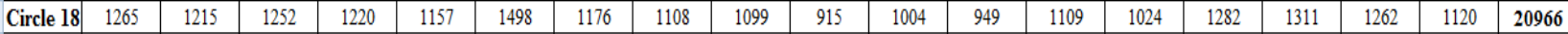

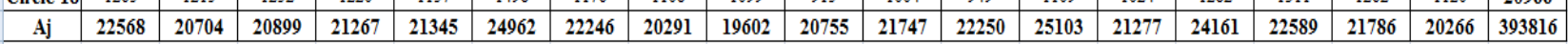

Table 3: Utility Matrix for Car

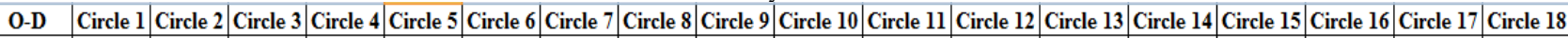

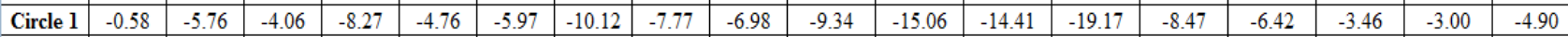

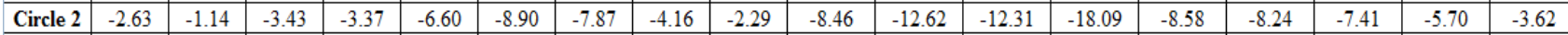
\begin{tabular}{|l|l|l|l|l|l|l|l|l|l|l|l|l|l|l|l|l|l|l|}
\hline Circle 3 & -11.10 & -3.25 & -1.55 & -3.16 & -5.01 & -7.34 & -8.59 & -4.88 & -4.54 & -10.89 & -13.89 & -14.30 & -21.80 & -9.97 & -10.39 & -9.55 & -8.30 & -6.37 \\
\hline Cirle & -7.66 & -3.48 & -2.41 & -1.32 & -3.9 & -6.53 & -6.73 & -2.9 & -1.69 & -7.43 & -11.74 & -1233 & -15.62 & -9.16 & -9.57 & -8.44 & -7.46 & -488 \\
\hline
\end{tabular}

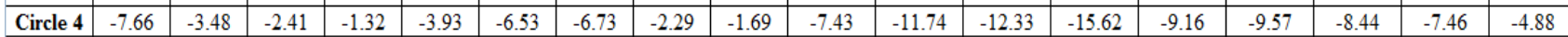

\begin{tabular}{|l|l|l|l|l|l|l|l|l|l|l|l|l|l|l|l|l|l|l|}
\hline Circle 5 & -10.85 & -6.55 & -4.02 & -4.04 & -1.76 & -3.63 & -6.33 & -4.42 & -5.60 & -8.89 & -13.48 & -13.30 & -13.23 & -11.97 & -12.29 & -12.18 & -12.21 & -9.30 \\
\hline
\end{tabular}

\begin{tabular}{|l|l|l|l|l|l|l|l|l|l|l|l|l|l|l|l|l|l|l|}
\hline Circle 6 & -19.31 & -9.45 & -7.55 & -6.67 & -3.72 & -0.64 & -4.14 & -6.17 & -7.23 & -7.62 & -7.79 & -10.75 & -12.26 & -9.96 & -10.95 & -10.97 & -11.25 & -8.68 \\
\hline
\end{tabular}

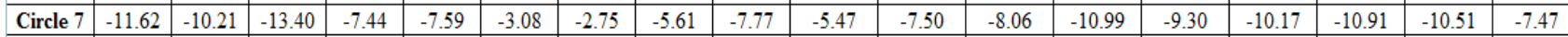

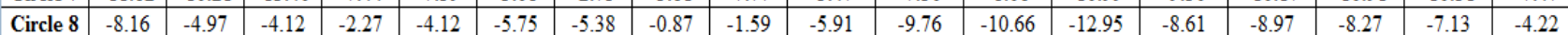

\begin{tabular}{|l|l|l|l|l|l|l|l|l|l|l|l|l|l|l|l|l|l|l|}
\hline Circle 9 & -6.54 & -2.68 & -3.49 & -1.94 & -4.64 & -6.79 & -6.47 & -2.39 & -1.08 & -6.62 & -11.46 & -11.24 & -13.72 & -9.40 & -9.05 & -7.81 & -6.59 & -4.14 \\
\hline
\end{tabular}

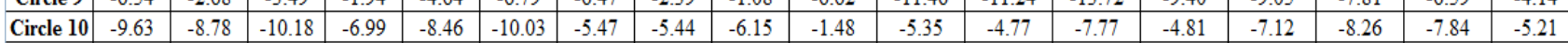

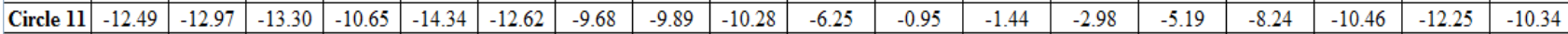

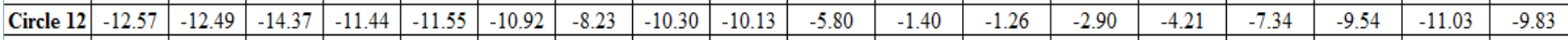

\begin{tabular}{|l|l|l|l|l|l|l|l|l|l|l|l|l|l|l|l|l|l|l|}
\hline Circle 13 & -18.96 & -20.76 & -17.76 & -16.60 & -4.47 & -10.64 & -10.47 & -15.05 & -16.05 & -8.18 & -3.54 & -3.02 & -0.80 & -6.39 & -12.68 & -13.16 & -15.38 & -13.55 \\
\hline
\end{tabular}

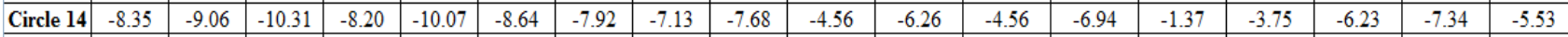

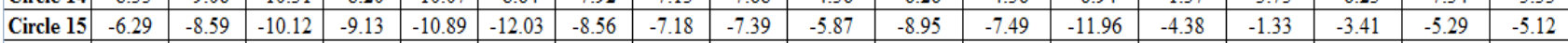

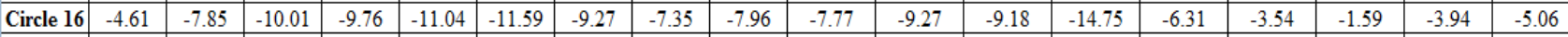

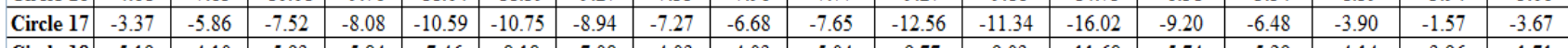

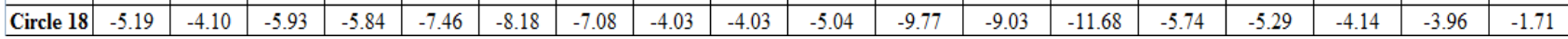

Table 4: Utility Matrix for Two Wheeler

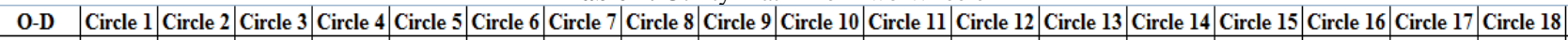

\begin{tabular}{|c|c|c|c|c|c|c|c|c|c|c|c|c|c|c|c|c|c|c|}
\hline ircle l & -0.65 & -2.23 & -2.49 & \begin{tabular}{|c|}
-3.91 \\
\end{tabular} & \begin{tabular}{|l|}
-3.73 \\
\end{tabular} & \begin{tabular}{|l|}
-4.28 \\
\end{tabular} & -4.56 & -3.69 & $\begin{array}{l}-3.12 \\
\end{array}$ & -4.95 & -6.88 & -6.35 & -6.35 & -3.78 & -3.08 & -1.39 & -1.12 & -2.22 \\
\hline Circle 2 & $\begin{array}{l}-1.79 \\
\end{array}$ & -0.53 & -1.17 & $\begin{array}{l}-1.61 \\
\end{array}$ & -2.93 & -4.10 & -3.82 & -1.90 & -0.85 & -3.85 & -6.16 & -5.62 & -7.02 & -4.18 & -3.92 & -3.39 & -2.06 & -1.33 \\
\hline Circle 3 & -4.32 & -1.09 & -0.71 & -1.28 & -2.24 & -2.87 & -4.0 & -2.34 & -2.1 & -5.01 & -5.48 & -6.64 & -9.52 & $\begin{array}{l}-5.43 \\
\end{array}$ & -5.26 & -4.74 & -3.71 & 2.80 \\
\hline & -3.53 & -1.47 & -1.01 & -0.59 & -1.74 & -2.95 & -3.19 & -1.06 & -0.76 & -4.24 & -5.14 & -6.76 & -8.2 & 5.34 & -5.54 & 4.53 & 43 & 2.41 \\
\hline & $\begin{array}{l}-6.07 \\
\end{array}$ & -3.18 & -1.74 & -1.43 & -0.77 & 32 & -3.12 & -2.15 & -2.0 & 4.1 & -4.6 & -5.08 & 54 & 3.0 & & 7.32 & -5.61 & 4.73 \\
\hline Circle 6 & $\begin{array}{l}-6.72 \\
\end{array}$ & -4.4 & -3.10 & -2.78 & -1.32 & -0.56 & -2.34 & -2.94 & -3.6 & -3.4 & -2.8 & -3.1 & -4.3 & -4.6 & & 5.5 & 9 & -4.71 \\
\hline Circle 7 & -6.15 & -5.02 & -5.71 & \begin{tabular}{|l|}
-3.28 \\
\end{tabular} & -2.64 & -1.0 & -1.32 & -2.6 & -3.7 & -2.6 & -2.7 & -3.3 & -4. & 1. & 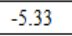 & -6.42 & 7 & -4.26 \\
\hline Circle 8 & \begin{tabular}{|l|}
-4.21 \\
\end{tabular} & -2.21 & -2.18 & \begin{tabular}{|c|}
-0.87 \\
\end{tabular} & \begin{tabular}{|l|}
-2.06 \\
\end{tabular} & -2.96 & -2.87 & -0.52 & -1.0 & -2.96 & -4.98 & -5.8 & -6.1 & -4.1 & -4.8 & -4.21 & -3.27 & -1.92 \\
\hline & -3.02 & -1.04 & -1.70 & -1.27 & -2.3 & -3.7 & -3.6 & -1.1 & -0.5 & -3.6 & -6.2 & -6.0 & -7. & -4.6 & -5. & -4.32 & 2.81 & -1.77 \\
\hline 10 & -4.70 & -3.94 & -4.61 & -3.75 & -3.97 & -6.40 & -2.9 & -2.3 & -3.0 & -0.7 & -1.9 & -1.9 & -3. & -2 & -3. & -3.82 & 3.90 & -2.59 \\
\hline 11 & -5.97 & -6.21 & -6.83 & -5.31 & -5.27 & -7.49 & -4.48 & -4.7 & -4.8 & -3.47 & -0.6 & -0.6 & -1.0 & -2.8 & -4 & 28.14 & -6.03 & -4.65 \\
\hline e 12 & -6.66 & -6.46 & -7.06 & -5.93 & -4.98 & -4.49 & -6.17 & -5.05 & -5.14 & -2.79 & -0.6 & -0.4 & -1. & -2. & -3 & -4.83 & -5.61 & -4.95 \\
\hline & -6.21 & -5.77 & -6.02 & -6.56 & -5.29 & -3.60 & -4.05 & -5.9 & -6.6 & -3.8 & -1.3 & -1. & -0 & -2 & -4 & -3.22 & 8 & -6.57 \\
\hline & -4.16 & -4.12 & -5.28 & -4.64 & -4.58 & -3.63 & -23.30 & -3.52 & -3.6 & -1.9 & -2.7 & -2. & -2 & -0 . & -1. & 26 & 1 & -3.16 \\
\hline 15 & -2.86 & -4.07 & -4.69 & -4.66 & -5.25 & -5.95 & -3.95 & -3.64 & -3.80 & -2.8 & -4.0 & -3.5 & -5.2 & -1.9 & -0.8 & 1.56 & -2.69 & -2.36 \\
\hline e 16 & -2.43 & -4.19 & -5.12 & -5.59 & -5.53 & -6.67 & -4.89 & -3.91 & -3.94 & -4.08 & -5.07 & -4.79 & -6.22 & -3.36 & -1.87 & -0.55 & -2.20 & -2.75 \\
\hline cle 17 & -1.94 & -2.49 & -3.72 & \begin{tabular}{|l|l|}
-4.18 \\
\end{tabular} & -5.38 & -5.20 & -4.64 & -3.32 & -3.21 & -4.05 & -5.93 & -5.61 & -7.47 & -4.24 & -3.63 & -2.13 & -0.67 & -1.73 \\
\hline Circle 18 & -2.89 & -1.91 & -2.96 & -3.19 & -3.24 & -4.08 & -3.31 & -1.91 & -1.60 & -2.10 & -4.54 & -4.10 & -5.32 & -2.54 & -2.62 & -1.92 & -1.73 & -0.92 \\
\hline
\end{tabular}


Table 5: Utility Matrix for Bus

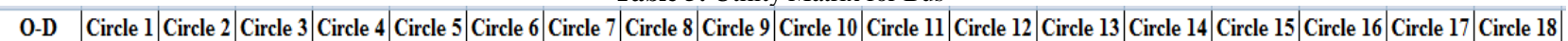

\begin{tabular}{|c|c|c|c|c|c|c|c|c|c|c|c|c|c|c|c|c|c|c|}
\hline Circle l & -0.74 & -3.89 & -6.09 & -6.61 & -5.91 & -8.94 & -6.23 & -5.52 & -4.95 & -6.06 & -7.40 & -7.64 & -9.90 & -6.34 & -6.84 & -3.64 & -2.48 & -3.98 \\
\hline Circle 2 & -4.11 & -0.91 & -1.97 & -3.22 & -3.81 & -5.52 & -5.23 & -3.02 & -1.81 & -5.07 & -6.64 & -6.34 & -9.19 & -5.61 & -6.47 & -4.52 & -3.66 & -2.85 \\
\hline Circle 3 & -6.78 & -1.85 & -2.25 & -2.10 & -3.36 & -7.15 & -5.18 & -2.60 & -2.38 & -5.36 & -7.27 & -8.03 & -6.79 & -6.06 & -7.93 & -5.97 & -5.14 & -3.80 \\
\hline Circle 4 & -6.63 & -2.48 & -1.66 & -1.64 & -2.83 & -5.92 & -4.67 & -2.05 & -1.58 & -4.35 & -6.21 & -7.57 & -5.96 & -5.37 & -6.96 & -5.13 & -4.45 & -3.29 \\
\hline \begin{tabular}{|l|} 
Circle 5 \\
\end{tabular} & -6.92 & -4.46 & -3.31 & -2.45 & -2.19 & $\begin{array}{l}-5.35 \\
\end{array}$ & -5.21 & -2.98 & -3.24 & -5.06 & -7.18 & -7.36 & -9.60 & -6.36 & -8.02 & -6.36 & -5.13 & -4.03 \\
\hline Circle 6 & -8.27 & -6.62 & -1.93 & -5.72 & -3.37 & -0.61 & -5.42 & -5.29 & -5.78 & -6.72 & -7.82 & -9.27 & -10.72 & -8.08 & -10.31 & -9.60 & -8.39 & -7.35 \\
\hline Circle 7 & -6.29 & -5.74 & -1.18 & -4.72 & -4.64 & -2.84 & -2.91 & -3.01 & -4.34 & -3.91 & -4.54 & -6.45 & -8.37 & -5.48 & $\begin{array}{l}-7.02 \\
\end{array}$ & -6.24 & -5.92 & -4.26 \\
\hline Circle 8 & -5.87 & -2.19 & -2.09 & -1.41 & -3.01 & -3.22 & -3.84 & -1.08 & -1.26 & -2.81 & -5.75 & -6.56 & -7.79 & -4.35 & -6.43 & -4.97 & -3.98 & -2.73 \\
\hline \begin{tabular}{|l|l} 
Circle 9 \\
\end{tabular} & -5.13 & -1.34 & -2.82 & -1.93 & -2.68 & -3.93 & -3.62 & -1.78 & -0.92 & -3.47 & -5.49 & -6.33 & -7.93 & -4.73 & $\begin{array}{l}-6.33 \\
\end{array}$ & -5.24 & -4.12 & -2.84 \\
\hline Circle 10 & -5.57 & -5.09 & -5.44 & -4.93 & -4.89 & -7.29 & -4.51 & -3.80 & -3.91 & -1.59 & -3.63 & -2.74 & $\begin{array}{l}-4.44 \\
\end{array}$ & -3.07 & -5.39 & -5.80 & -5.20 & -3.57 \\
\hline Circle 11 & -6.13 & -6.08 & -7.22 & -6.53 & -6.31 & -8.21 & -5.83 & -4.95 & -4.99 & -3.71 & -2.68 & -1.04 & -2.36 & -3.26 & -5.36 & -6.25 & -5.98 & -4.92 \\
\hline Circle 12 & -7.63 & -6.53 & -8.03 & -7.32 & -7.48 & -8.92 & -6.82 & -6.13 & -5.88 & -4.55 & -2.00 & -1.39 & -2.15 & -3.57 & -5.70 & -7.07 & -6.61 & -5.58 \\
\hline Circle 13 & -6.22 & -9.26 & -9.26 & -9.23 & -9.02 & -10.67 & -9.58 & -8.02 & -8.71 & -6.90 & -3.60 & -2.80 & -1.88 & -4.38 & -7.56 & -8.29 & -8.78 & -8.05 \\
\hline Circle 14 & -6.01 & -5.63 & -6.23 & -5.97 & -5.96 & -6.63 & -5.81 & -4.68 & -4.78 & -3.58 & -3.97 & -3.39 & -4.10 & -2.33 & -3.69 & -5.00 & -5.31 & -4.23 \\
\hline Circle 15 & -6.54 & -6.51 & -7.37 & -6.37 & -7.16 & -8.88 & -5.30 & -5.67 & -5.30 & -5.58 & -5.16 & -6.59 & -9.31 & -4.18 & -2.58 & -5.09 & -5.04 & -4.34 \\
\hline Circle 16 & -4.63 & -5.21 & -5.60 & -5.99 & -6.54 & -7.95 & -6.17 & -5.43 & -4.53 & -5.28 & -8.33 & -7.03 & -9.15 & -5.27 & -4.87 & -1.87 & -3.77 & -3.60 \\
\hline Circle 17 & -3.40 & -3.63 & -4.89 & -5.01 & -5.82 & -6.65 & -5.87 & -4.98 & -3.72 & -5.46 & -6.50 & -6.25 & -10.32 & -6.10 & -6.25 & -4.73 & -3.52 & -2.77 \\
\hline Circle 18 & -5.21 & -4.59 & -5.35 & -4.79 & -4.65 & -7.32 & -4.67 & -3.55 & -3.60 & -1.83 & -3.90 & -3.18 & -4.82 & -3.12 & -5.15 & -5.14 & -4.84 & -3.13 \\
\hline
\end{tabular}

The probability of selection of different modes has been calculated using the following equations and the Probability of different modes are as shown in figures 6,7 and 8 for different modes. The Probability of modes selection depends on the vehicle operation cost, purpose of the trip, traffic congestion and size of the family etc. In this study total travel cost for the individual mode has been consider to know the probability of each mode.

Probability Of CAR $=\frac{\mathrm{e}^{\mathrm{TTC}(\mathrm{CAR})}}{\mathrm{e}^{\mathrm{TTC}(\mathrm{CAR})}+\mathrm{e}^{\mathrm{TTC}(\mathrm{BUS})}+\mathrm{e}^{\mathrm{TTC}(\mathrm{TW})}}$

$$
\begin{aligned}
& \text { Probability Of BUS }=\frac{\mathrm{e}^{\mathrm{TTC}(\mathrm{BUS})}}{\mathrm{e}^{\mathrm{TTC}(\mathrm{CAR})}+\mathrm{e}^{\mathrm{TTC}(\mathrm{BUS})}+\mathrm{e}^{\mathrm{TTC}(\mathrm{TW})}} \\
& \text { Probability Of TW }=\frac{\mathrm{e}^{\mathrm{TTC}(\mathrm{TW})}}{\mathrm{e}^{\mathrm{TTC}(\mathrm{CAR})}+\mathrm{e}^{\mathrm{TTC}(\mathrm{BUS})}+\mathrm{e}^{\mathrm{TTC}(\mathrm{TW})}}
\end{aligned}
$$

Where TTC is the Total Travel Cost

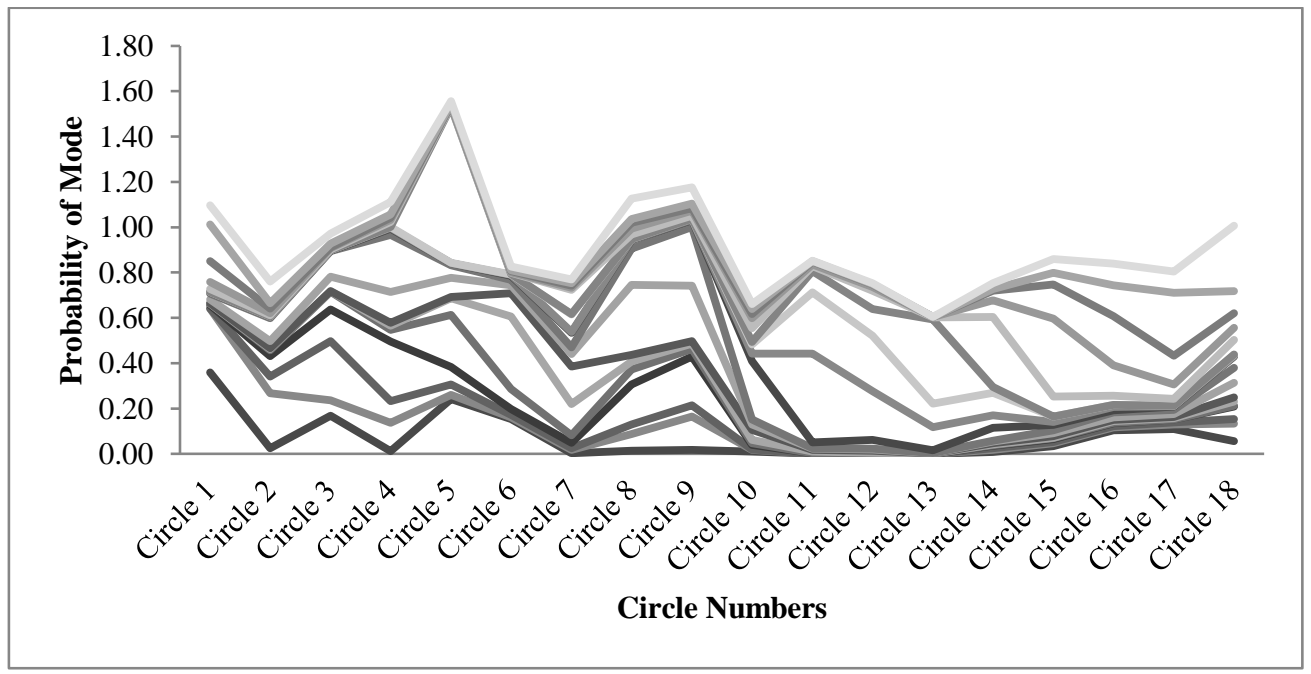

Fig. 2: Probability of Car.

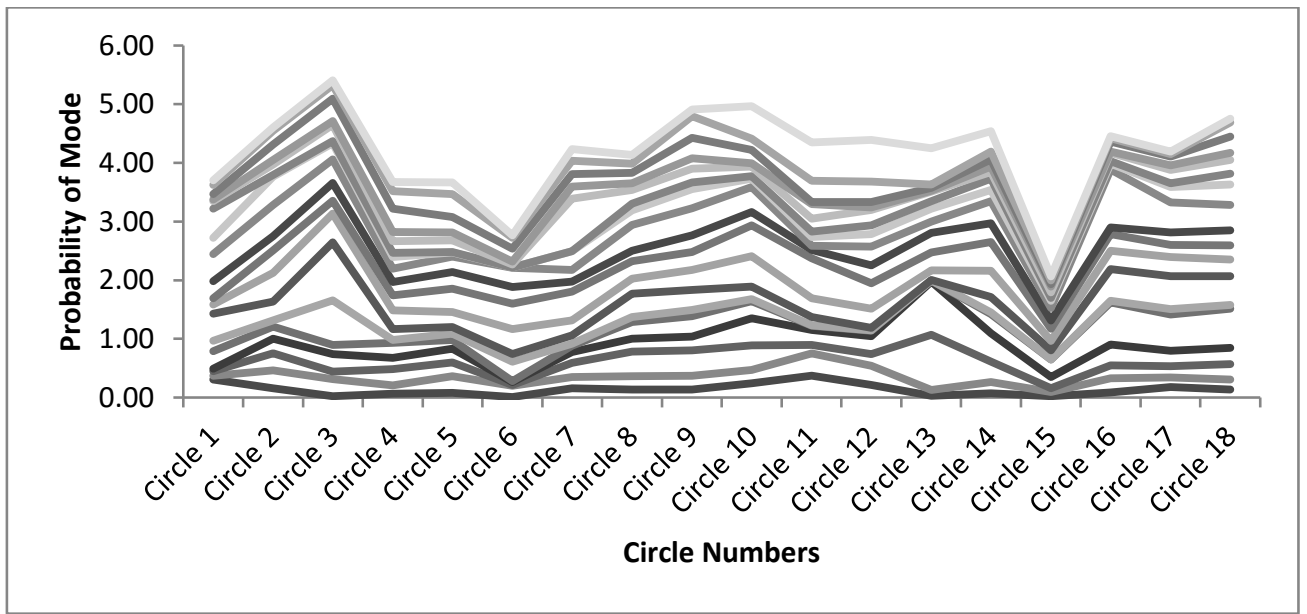

Fig. 3: Probability of Bus. 


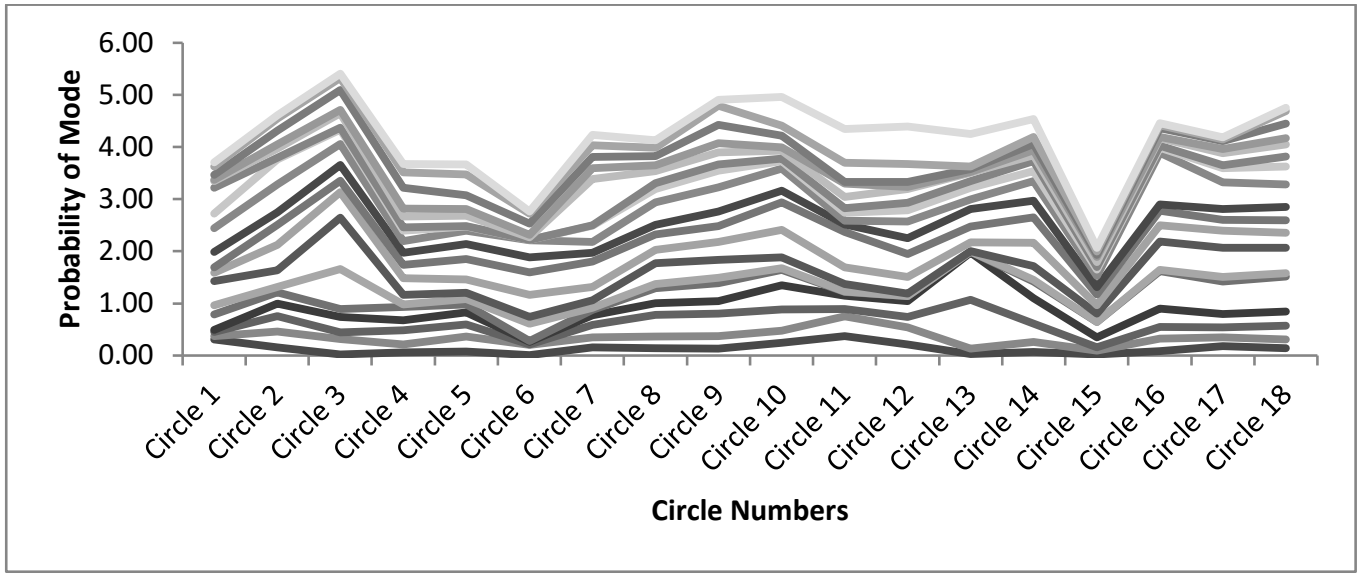

Fig. 4: Probability of Two Wheeler.

Modal Share of any Mode $=$ Total Trips $\times$ Probability of that mode

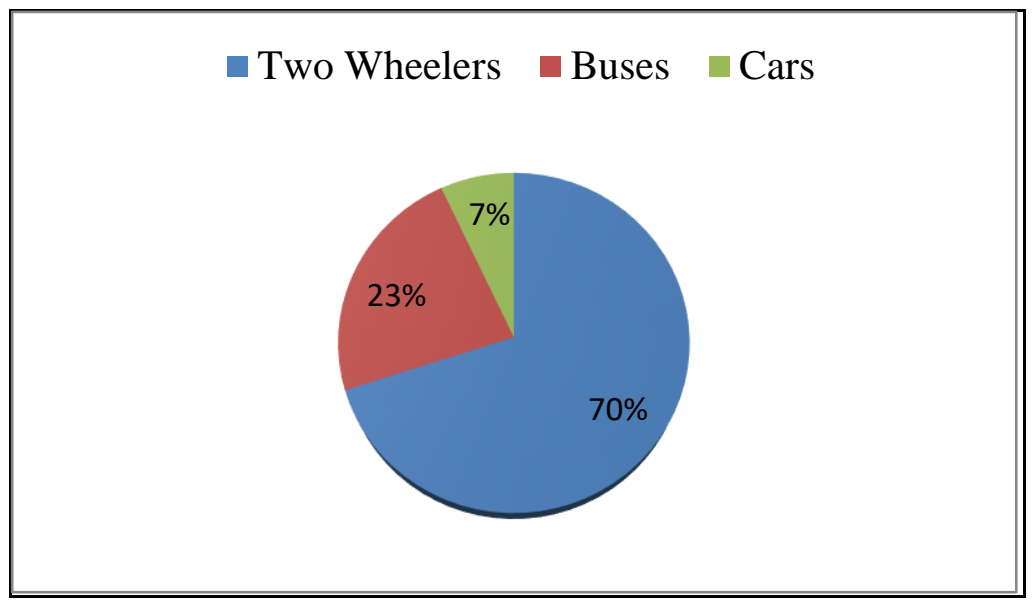

Fig. 5:Modal Share of the Trips.

\section{Conclusions}

From the study it has been observed that the modal share of 2 wheeler is $70 \%$, bus is about $23 \%$ and car is about $7 \%$ of the total trips. It means mode choice of road user mainly depends on the income level of the individual. Low income group users are preferred to use 2- wheeler and it influences highly on cars and buses. Only high income group users are preferred to use cars and female road users are used buses in safety point of you.

\section{References}

[1] Ashiabor, S., H. Baik and A. Trani, 2007. Logit Models to Forecast Nationwide Intercity Travel Demand in the United States. Transportation Research Record: Journal of the Transportation Research Board, No. 2007, Transportation Research Board of the National Academies, Washington, D.C., pp: 1-12.

[2] Forinash, C.V. and F.S. Koppelman, 1993. Application and interpretation of nested logit models of intercity mode choice. Transport. Res. Record, 1413: 98-106.

[3] Grayson, A., 1981. Disaggregate model of choice in intercity travel. Transport. Res. Record, 835: 36-42.

[4] Mandel, G. and Rothengatter, 1997. A disaggregate box-cox logit mode choice model of intercity passenger travel in Germany and its implications for high-speed rail demand forecasts. Ann. Region. Sci., 31: 99-120.

[5] Praveen, K.M. and C. Mallikarjuna, 2011. Mode choice modelling for intercity transportation in India: A case of Guwahati to five metro cities. Int. J. Earth Sci. Eng., 04(06): 364-374.

[6] Wilson, R.F., S. Damodaran and J.D. Innes, 1990. Disaggregate mode choice models for intercity passenger travel in Canada. Canadian J. Civil Eng., 17: 184-191.
[7] Cornelia Richter, Stephan Keuchel, 2012, Modelling Mode Choice in Passenger Transport with Integrated Hierarchical Information. Journal of Choice Modeling, 5(1), 2012, pp1-21

[8] Madhu, D. 2008. Fuzzy Logic Based Micro-Scopic Traffic Simulation Model for Transport Policy Evaluation. Gifu University, Japan: $\mathrm{PhD}$ Thesis.

[9] Omer Khan, 2007. Modelling Passenger Mode Choice Behavior Using computer Aided Stated Preference Data, School of Urban Development, Queensland University of Technology, Queensland: PhD Thesis.

[10] Xiao-Shan Lu, Hai-Jun Huang*, Tian-Liang Liu. Pricing and hierarchical logit-based mode choice models in a multimodal corridor with trip-chain costs. Beijing University of Aeronautics \& Astronautics, Beijing 100191, China. Systems Engineering Procedia 2 (2011) 231 - 242https://doi.org/10.1016/j.sepro.2011.10.031.

[11] Horowitz. J. L (1991) Reconsidering the Multinomial Probit Model. Transportation Research part B: Methodological, 26(6), PP 433 438.https://doi.org/10.1016/0191-2615(91)90036-I.

[12] Zhihu Zhang, Hongzhi Guan, Huanmei Oin and YungiangXue (2013) A Traffic Mode Choice Model for the Bus user Groups Based on SP and Rp Data. 13th COTA International conference of Transportation Professionals (CICTP 2013), Elsevier 96(2013), PP 382-389.https://doi.org/10.1016/j.sbspro.2013.08.045.

[13] Yaowuwang, chuan ding, chaoliu,bingleixie (2013) an analysis of international freight mode choice between truck and rail : a case study of mary land, united states.13th COTA International conference of Transportation Professionals (CICTP 2013), Elsevier 96(2013), PP 1239-1249.

[14] Winston c. (1983). The demand for freight transportation: models and applications. Transportation Research part A, volume 17, no .6, PP 419-427.https://doi.org/10.1016/0191-2607(83)90162-0.

[15] Shen.g and wang.j (2012). A freight mode choice analysis using a binary logit mode and gis: the case of creal grains transportation in the united states. Journal of Transportation Technologies, 2, PP 175-188.https://doi.org/10.4236/jtts.2012.22019. 
[16] Samimi, A. Kawamura,K, and Mohhammadian, A. (2011). A disaggregate analysis of rail-truck mode choice behaviors for freight shipments. The 90th Transportation Research Board Annual Meeting, CD-ROM, Washing ton D.C.

[17] Philippe Gerber, HichemOmrani, Omar choarit, Anjali Awasthi. (2012). Predection of individual travel mode using evidential neural network model PP 1-17.

[18] JianchuanXiamyu (2013) An exploration of the interdependencies between trip changing behavior and travel mode choice 13th COTA International conference of Transportation Professionals (CICTP 2013), Elsevier 96(2013), pp. 1967-1975.

[19] Chandra R. Bhat, Alessamdroportoghese, Erika Spissu, Naveen Eluru, ItaloMeloni (2010), A Copula-Based joint model of commute mode choice and number of Non-work trips during the commute. PP 1-15.

[20] Manssour A. Abdulsalam Bin Miskeen, Ahmed Mohamed Alhodairi, Rizaatiq Abdullah Bino and Rahmat. K (2013). Modeling a Multinomial logit Model of Intercity Travel Mode Choice Behavior for all trips in Libiya, International Journal of Civil Science and Engineering Vol: 7, No: 9 PP 132-141.

[21] Mukesh Kumar, PradipSarkar, ErrampalliMadhu (2013). Development of Fuzzy Logic Based Mode Choice Model Considering Public transport policy options, International Journal for traffic and Transportation Engineering, 3(4): PP 408-425.

[22] L. A. Zadeh, (1965) "Fuzzy sets" Information and control volume 8, No.3, PP 338-353.https://doi.org/10.1016/S0019-9958(65)90241-X

[23] ArunotayanunKriankrai, Johnw.Polak (2011), Taste Heterogencity and market segmentation in freight shippers' mode choice behavior, Transportation research part E: Logistics and transportation review, Elsevier, volume 47, Issue 2, PP 138-148. 